\title{
Identification and Ranking Paramount Factors Affecting the Organizational Health Using AHP Method (Case Study: Gas Transmission Office in Area 7)
}

\author{
Maryam Asgharinajib ${ }^{1}$, Rohollah Sohrabi ${ }^{2}$ \& Kambiz Hamidi ${ }^{1}$ \\ ${ }^{1}$ Department of Management, Faculty of Humanities, Islamic Azad University of Hamedan, Hamedan, Iran \\ ${ }^{2}$ Faculty of Economics and Social Science, Bu Ali Sina University, Hamedan, Iran \\ Correspondence: Maryam Asgharinajib, Department of Management, Faculty of Humanities, Islamic Azad \\ University of Hamedan, Hamedan, Iran. E-mail: maryam.asgharinajib@yahoo.com
}

\author{
Received: November 28, 2015 Accepted: December 17, 2015 Online Published: February 23, 2016 \\ doi:10.5539/ass.v12n3p71 \\ URL: http://dx.doi.org/10.5539/ass.v12n3p71
}

\begin{abstract}
The organizational health is amongst the overriding concepts in management employed to indicate the overall condition of organizations and companies. Organizational health in national organizations would culminate into appropriate decisions, policy-making and due application of policies. Hence, the aim of this study was to identify and rank paramount factors affecting the organizational health.

The data gathering instrument was researcher-made questionnaires. 500 questionnaires were distributed among the employees of Gas Transfer Office in Area 7 and 230 of them were collected and analyzed by virtue of structural equations modeling in LISREL Software. The verification procedure was carried out through the "Pearson Correlation Test" using SPSS. The ranking of aforementioned factors was carried out through the use of AHP analysis in Expert Choice Software.

The results showed that there was a significant relationship between organizational health and the factors such as trust, motivation, responsiveness, reputation, capabilities, outward tendency, path-objective, collaboration, coordination, innovation, ethics, communication, commitment, leadership, performance identifying ,culture, employee effectiveness, and, resource usage. The final model was validated. Also, the final model was validated. Communication factor is ranked as the first paramount factor while capability factor is the 18th factor.
\end{abstract}

Keywords: organizational health, Gas Transmission Office in Area 7

\section{Introduction}

The prerequisite for the organizations to sustain and develop is to be well-equipped with advanced tools to tackle the ever-increasing challenges of the modern world. It is axiomatic that today's complex problems could not be solved by former tools. Toffler said "nothing is more dangerous than yesterday's success" (Latifi, 2004). As an individual requires health to survive and carry out responsibilities, an organization is also deemed as an organic and animate entity which requires organizational health in order to attain its ultimate objectives. If this desirable health is not provided, the achievement of objectives will be challenging if not impossible (Ghorban Shiroudi, 2011). A manager who does not possess some criteria to monitor the organizational health resembles an aviator who embarks on a blind flight (Latifi, 2004). As a result, the identification of factors affecting organizational health can help managers to make decisions and achieve the goals of the organization. Health in organizations, especially organizations that deal more with human resources is very important (Farahbakhsh, 2009). Because of the special role of energy in the public welfare and the large number of workforce at Gas Transmission Office in Area 7 and their prominent role in serving, the need for studying the organizational health would be important at that organization. So, the aim of this study was to assess, identify, and rank the factors affecting organizational health at Gas Transmission Office in Area 7.

\section{Literature Review}

\subsection{Organizational Health}

Organizational health is not a novel theme. In 1958 Argeris initiated a debate regarding "How an organization acquires health" (Argeris, 1958). By 1990 a limited number of researches concerning organizational health have 
been done. Since then, the scope of studies has expanded drastically, specifically when concepts such as organization capacity, organizational health, work environment health, occupational health, and healthy organization were introduced to the realm of social sciences and management (Miandari et al., 2012).

Although organizational health, as stated in the literature, is mainly centered around employees; however, a gradual advancement from individual health towards managerial processes, culture, structural health, and a concentration on psychological factors, adaption to work environment, employees' satisfaction, leadership, trust, mutual support, social responsibility, and effectiveness has been observed (Ansari et al., 2009).

Organizational health has not been stated explicitly in the literature. Bennis (1962) was one of the pioneer researchers who propounded the necessity of incorporating the concept of organizational health in organizations. Bennis (1962) highlighted that conventional approaches for assessing the organizational effectiveness were not sufficient enough to reflect the broader depth of organizational health. When Bennis applied the psychological health concept to the structure of organizations, he identified 3 major dimensions of the organizational health namely adaptability, coherence of identity, and ability to embrace the surrounding environment correctly (MacIntosh \& Burns, 2007).

Later, the organizational health was firstly applied by Miles (1969 as cited in Korkmaz, 2007) when conducting studies on organizational atmosphere in schools. From Miles's view, organizational health refers to a broader situation than immediate the effectiveness of the organization and it encompasses an array of sustainable attributes including durability and sustainability of organization, adaptability, development, and expansion of the organizational capability. The term organizational health was first used to tefer to the sustainability and the maintenance of the organization. However, based on research of Parsons (1950), Hoy, Miskel (2003) and Hoy, Tarter (1997) used it to mean the adaptability of the organization to the environment (Korkmaz, 2007; Saedi et al., 2010; Jahed, 2005).

Every individual has his or her own definition of health (Larson, 1999). However, whenever one intends to provide a concrete definition, it is to some extent less evident what the real meaning of health is (Terick, 2002). In the literature, the term "organizational health" is often used to delineate the aspects of work environments related to employees' health (Miller et al., 1999). Miller et al. used the organizational health to explain the occupational stress; while, Cotton and Hart (2003) interpreted the organizational health as the employees' health. While there is not any association between organizational health and management fields, in industry such relationship was demonstrated by Lencioni who defined the organizational health as the convergence of management, operation, strategy, and culture in an organization (Lencioni, 2012).

However, a few definitions concerning the healthy organization are presented for more clarification.

Lynden and Klingle highlighted that organizational health is a rather novel concept and it not only encompasses organization's capabilities to perform its tasks effectively but also entails the ability to improve and develop. In healthy organizations, employees with commitment, enthusiasm, open communication, and superior level of success can be found and a healthy organization is an environment in which individuals are inclined to stay, work, be proud of it, and maintain their effectiveness (Lynden \& Klingle, 2000). The organizational health implies the organization's capability to attain its objectives in an environment where the organizational performance improvement and employees' welfare are valued. These two perspectives are different but their relation portrays the fact that an individual's challenges might impinge on others as well. The improvement of organizational performance will be attained through the realization of a systematic approach in organization's processes, ensuring the employees' welfare be it either job satisfaction or physical, psychological, and social health. In order for an organization to establish effective performance, it needs to have sufficient determination, proper change (whenever required), and inner development (Omoyemiju \& Adveniyi, 2011).

Ower denotes that the organizational health is applied as a background for the organizational environment and it is a concept regarded as a variable for the organizational effectiveness. Davis regards an organization as a healthy collection where employees feel that they can create values in their jobs and achieve personal success and aggrandizement. Employees prefer doing a task that can bring about inner happiness. Many employees strive for responsibility, more opportunities, and occupational success. They long to be listened to and be treated as every one of them is deemed as an indispensable asset. They want to be assured that their organization really pays attention to their needs and difficulties (Poulanyi, 2004).

Lencioni defines the healthy organization as a collection which eschews unhealthy connections and confusion, possesses a high level of dedication and effectiveness, has minimal workforce displacement, and, in comparison with an unhealthy organization, spends less capital for selection. He exposes four pillars of healthy organizations: establishing a united leadership team, inducing clarity in the organization, highlighting the importance of the 
organizational clarity, and reinforcing the organizational clarity using good-natured approaches (Lencioni, 2006).

Gilbert argued that the organizational health equal to the complex frameworks, managerial processes, information system, and activities required to be in compliance with organization's strategy (as cited in Dive, 2004). Dive affirms that a healthy organization takes heed of both organizational performance and employees' welfare (Dive, 2008).Williams considers various aspects of employees' welfare namely social, psychological, and physical welfare and he also asserts that employees' welfare entails promotion and the incentives to keep the employees in the organization (Williams, 1994).

Bruhn has valued health higher than individual levels and concentrated on organizational levels (culture, incentives, communication, leadership) (Bruhn, 2001). De Smet asserts that the concept of organizational health represents the mutual role of the organizations; implying that an organization not only attains its objectives but also achieves the potentiality to sustain its success. Hence, the capacity of a healthy organization is beyond the confines of proper performance and adaptable structure to the surrounding environment (De Smet et al., 2006). In healthy organizations individuals and groups achieve the stability and sustainability, and additionally have the advantage of remarkable progress. Haunschild affirms that healthy organizations are capable of maintaining organizational health for their employees. This necessitates the organizational health to exist in the first place as organizations must collaborate with others to realize their objectives through the establishment of effective communications (Haunschild, 2003). As a result, healthy organizations facilitate the welfare improvement of their employees. This also creates a gratifying environment in which diligence, dedication, and pursuit of perfection will come to fruition (Akbari et al., 2013).

Some researchers contend that healthy organizations need to be able to realize their ethic objectives, recognize the obstacles, and overcome those challenges. Healthy organizations should be realistic about their capabilities and current conditions, be flexible, and be able to exploit the best resources to tackle the undesirable predicaments (Saatchi, 1996, p. 101). As a result, organizational health is the manifest attribute of an organization to direct, execute and reconstitute at a faster pace than its competitors which in long term warrants the superior performance. In a survey research conducted by Keller, Price (2011), It was observed that the success level of those organizations which simultaneously monitored their performance and health, was approximately twice as those which merely concentrated on their performance. Undeniably, superior performance is an essential parameter for success; however, health is also deemed as a crucial factor. No organization can sustain for 10, 20, or 50 years lacking a decent level of health (Keller \& Price, 2011).

\subsection{Theoretical Framework}

Organizational health can be influenced by numerous factors which can be crucial for the organization to achieve its objectives, can culminate in organizational effectiveness, and ultimately can be useful for profitability and efficiency of the organization (Tsui \& Cheng, 1999). Thus, the conceptual model of the current research is premised on the statistical findings of Lyndlen and Klingle (2000) concerning the evaluation of organizational health at colleges in which eleven parameters have been presented and of which nine factors are chosen for this research which are as follows:1) communication 2) collaboration 3) commitment 4) Reputation 5) ethics 6) path-objective 7) leadership 8) Employees' efficiency improvement 9) resource usage 10) identify performance. Additionally supplemental parameters are incorporated in this research; hence, based on Zolghadrnasab (2005) factor of trust and based on the model of Keller and Price (2011) factors of Capabilities, culture, responsiveness, innovation, outward tendency, coordination and motivation have also been included. 


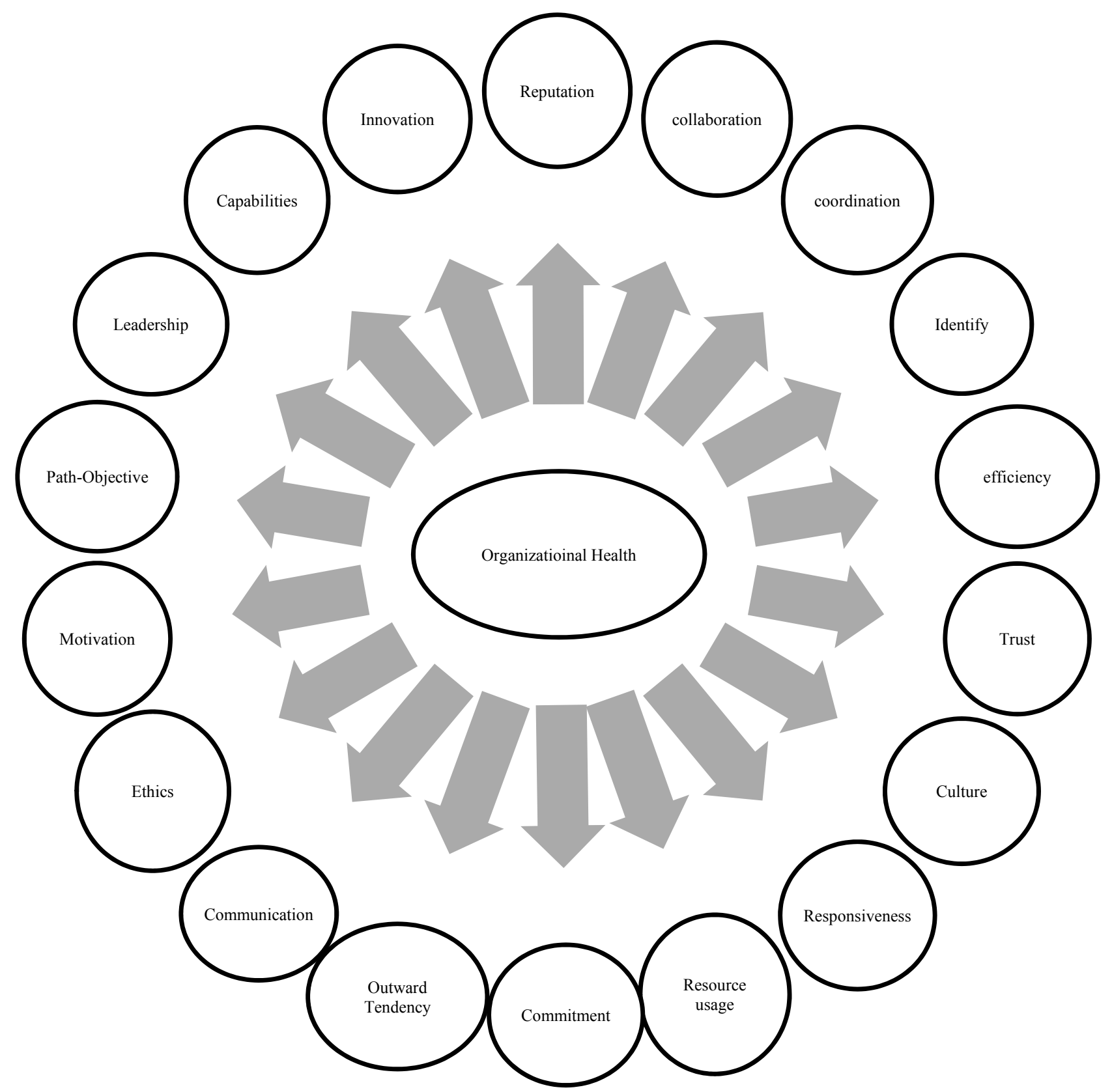

Figure 1. Theoretical framework

\subsection{Hypothesis}

1. There is a significant relationship between collaboration and involvement in organization and organizational health in the Gas Transmission Office in Area 7.

2. There is a significant relationship between communication and organizational health in the Gas Transmission Office in Area 7.

3. There is a significant relationship between reputation in organization and organizational health in the Gas Transmission Office in Area 7.

4. There is a significant relationship between commitment in organization and organizational health in the Gas Transmission Office in Area 7.

5. There is a significant relationship between employees' performance efficiency in organization and organizational health in the Gas Transmission Office in Area 7.

6. There is a significant relationship between resource usage in organization and organizational health in the Gas Transmission Office in Area 7. 
7. There is a significant relationship between ethics in organization and organizational health in the Gas Transmission Office in Area 7.

8. There is a significant relationship between leadership in organization and organizational health in the Gas Transmission Office in Area 7.

9. There is a significant relationship between path-objective in organization and organizational health in the Gas Transmission Office in Area 7.

10. There is a significant relationship between trust in organization and organizational health in the Gas Transmission Office in Area 7.

11. There is a significant relationship between coordination and control in organization and organizational health in the Gas Transmission Office in Area 7.

12. There is a significant relationship between culture in organization and organizational health in the Gas Transmission Office in Area 7.

13. There is a significant relationship between responsiveness in organization and organizational health in the Gas Transmission Office in Area 7.

14. There is a significant relationship between outward tendency in organization and organizational health in the Gas Transmission Office in Area 7.

15. There is a significant relationship between motivation in organization and organizational health in the Gas Transmission Office in Area 7.

16. There is a significant relationship between capabilities in organization and organizational health in the Gas Transmission Office in Area 7.

17. There is a significant relationship between innovation in organization and organizational health in the Gas Transmission Office in Area 7.

18. There is a significant relationship between identify performance in organization and organizational health in the Gas Transmission Office in Area 7.

19. Weight and ranking of the influential factors in organizational health in the Gas Transmission Office in Area 7 are not identical.

\section{Methodology}

\subsection{Sample and Instrumentation}

The statistical population in this research was the employees of the Gas Transmission Office in Area 7. The sampling method was the stratified sampling and the Cochran formula was utilized in order to determine the sample size. Library and survey methods of research were used to collect the required data. Questionnaires were the tools to obtain the aforementioned data. For employees' capability, outward tendency, resource usage, ethics, communication, trust, motivation, responsiveness, commitment, leadership, organization's reputation, culture, employees' efficiency, collaboration, innovation, coordination and path-objective the researcher-made questionnaires were used. Organizational health questionnaire was derived from the standard questionnaire of organizational health by Hoy and Feldman (1996). The number of 500 questionnaires were distributed among the employees of which 230 were returned and analyzed. For ranking a weight determination of each influential factor on organizational health the paired comparison questionnaire was applied. The latter questionnaire was distributed among 10 elite employees who were delegated key responsibilities in the organization under study. Reliability of data-gathering tool was measured by Cronbach's coefficient Alfa (0.714 for the organizational health questionnaire, 0.721 for the innovation questionnaire, 0.879 fot the trust questionnaire, 0.703 for the commitment, 0.736 for the culture questionnaire, 0.705 fot the collaboration, 0.785 for the responsiveness, 0.800 for the reputation questionnaire, 0.711 fot the efficiency questionnaire, 0.821 for the motivation questionnaire, 0.903 for the ethics questionnaire, 0.719 for the coordination, 0.966 for the communication questionnaire, 0.724 for the leadership questionnaire, 0.942 for the path-objective questionnaire, 0.924 for the resource usage questionnaire, 0.745 for the identify questionnaire, 0.701 for the outward tendency questionnaire, 0.742 for the capability questionnaire ).

\subsection{Methods}

Normality of data was confirmed by One-Sample Kolmogorov-Smirnov Test. To see whether the researcher s proposed model is verified or not was used. The purpose of the total goodness was to see to what extent the whole model is consistent with the used empirical data of the model was to determine the level of accordance 
between the model and the available data. There are vast arrays of criteria for goodness-of-fit that can be employed to measure the total fitness of the model. Unfortunately none of these criteria is the most viable and superior to the others, since a goodness-of-fit criterion would function completely differently depending upon the sample size, estimation method, model complexity, and assumptions of normality or a combination of them.

Consequently, different criteria could be employed for model fitting according to the model's conditions (Kalantari, 2009, pp. 128-129). The conceptual pattern of the current research was analyzed through the use of LISREL software utilizing path diagram and its diverse methods of fitting. A total model of SEM represents a combination of path diagram and CFA. Finally, a few goodness-of-fit criteria were used to fit the structural model of the principal hypotheses in this research.

In order to verify the research's hypotheses, the Pearson Correlation Test, was run using SPSS software. The significance level of variables was scrutinized by the use of Expert Choice software. In this stage, the initial hierarchical structure of the problem was created in the software by employing the required variables. Secondly, having inserted the experts' views and their evaluations into the structure, the variables were compared in pairs and their level of significance was determined.

\section{Results}

\subsection{The Main Hypothesis Testing}

As shown in Fig. 2, which displays the significant numbers of the structural model, it is evident that all of the relationships between organizational health and other variables are significant (owing to the significance levels higher than 1.96).

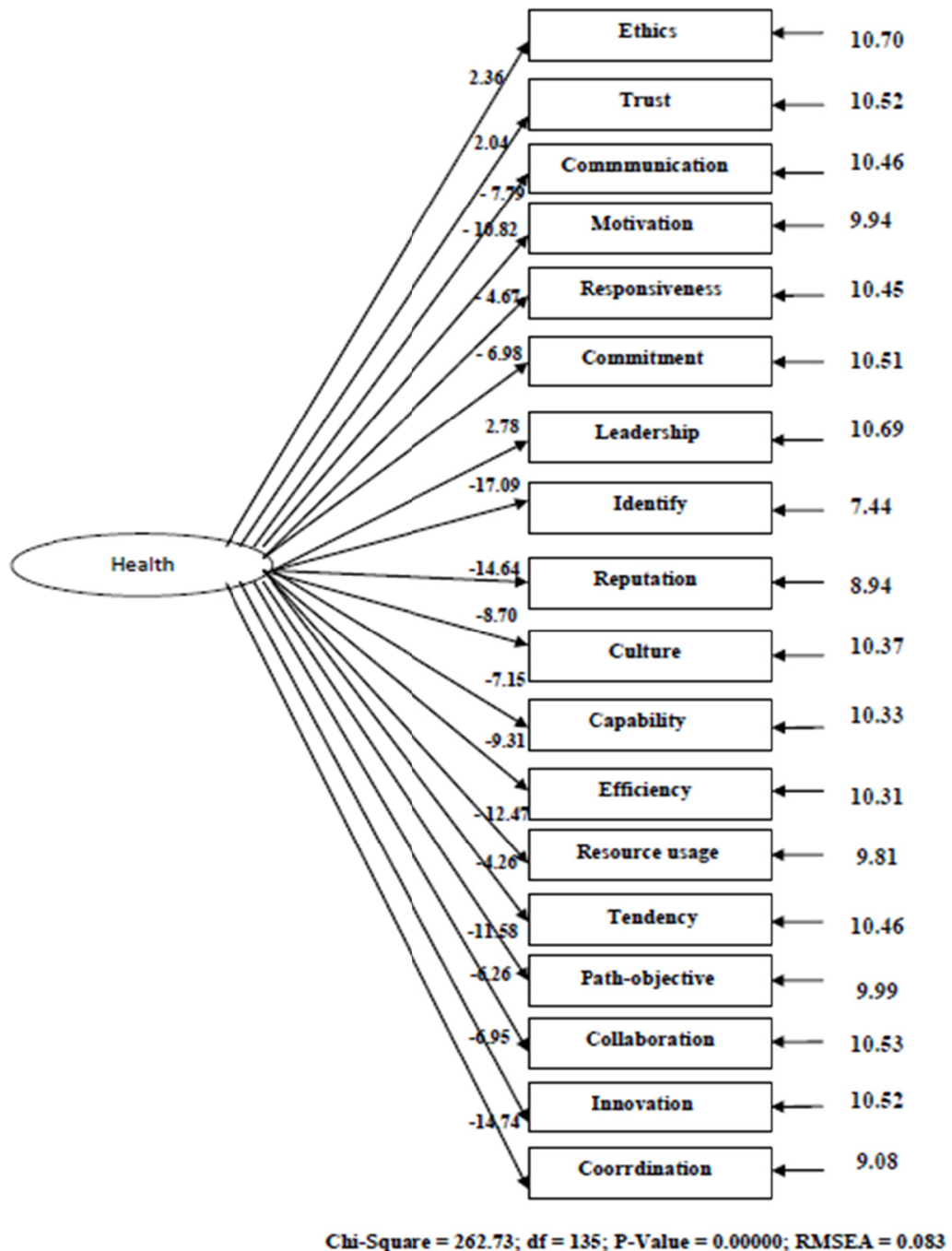

Figure 2. The significant numbers of the structural model 
In Figure 3 the structural model of the research is depicted by the standard coefficients. Regarding the final model, it is clear that the relationship among all of the criteria, presented in the initial theoretical model, indicates a significance level. Hence, all of the identified variables were corroborated as influential factors on the organizational health. Consequently, the final model of the research was validated.

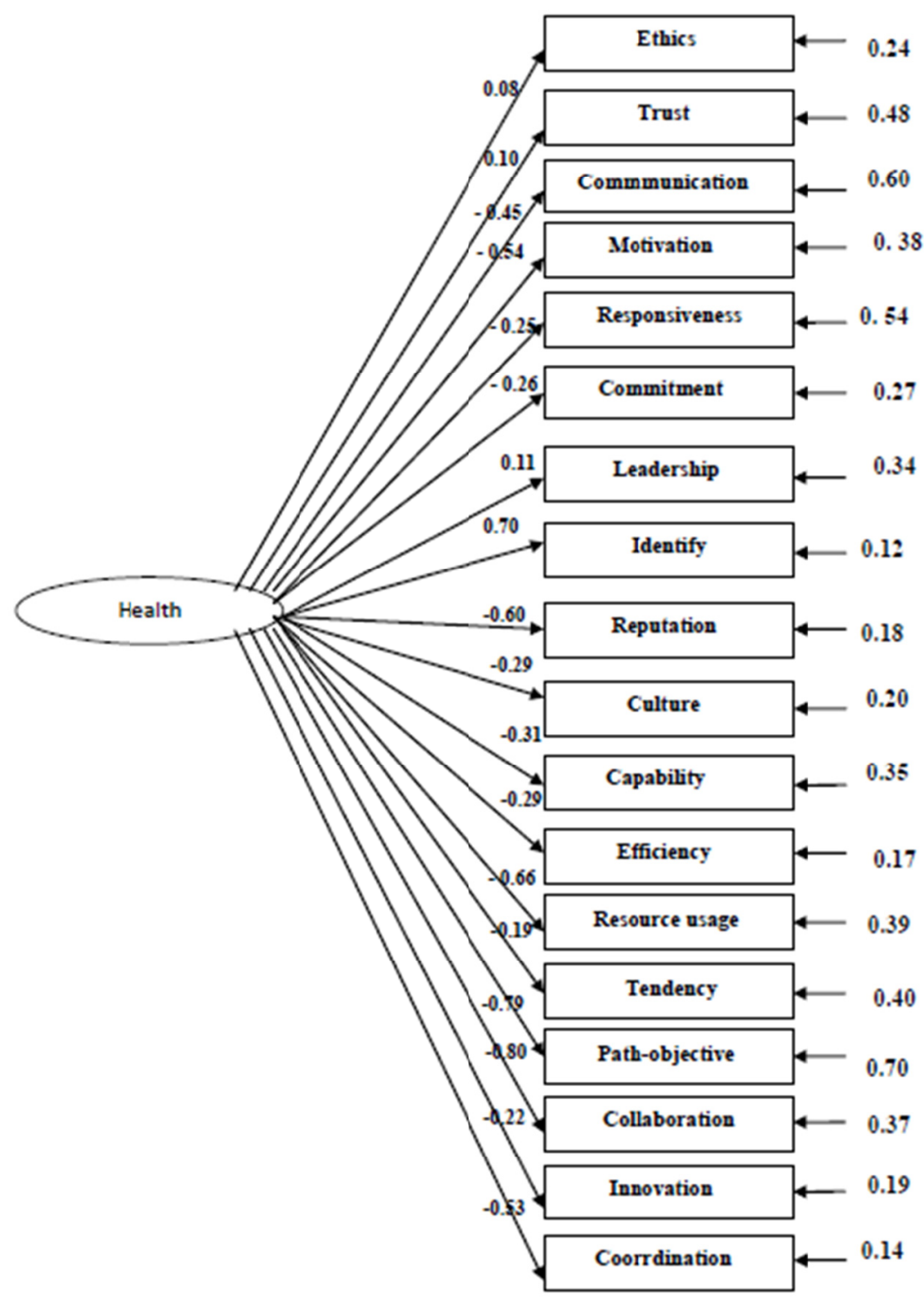

Chi-Square $=262.73 ; \mathrm{df}=135 ; \mathrm{P}-$ Value $=0.00000 ;$ RMSEA $=0.083$

Figure 3. Standard estimation coefficients of research's structural model

Although various classes of tests, known as fitting indexes, are being developed constantly, no optimized test has been accredited by researchers yet. As a result, different indexes have been introduced in numerous articles and researches (Houman, 2005). 1) GFI 2) Ratioof 3) Chi-Squared to Degree of freedom 4) NFI 5) AGFI. Principally, the above indexes are mostly influenced by extrinsic and unknown factors rather than inherent deficiency in fitting of the model (Anderson, 1988). Conversely, fitting indexes such as: 1) TLI 2) IFI 3) CFI 4) RMSEA 5) SRMR are less affected by extrinsic factors and the obtained results signify the deficiency of fitting (Houman, 2005 , p. 245). In general, if large number of indexes represent a good fitting, the research would be much valid and it can convince the readers of the model's suitability (Schreibera, 2006). Table 1 shows the most paramount fitting indexes. The results show that the conceptual pattern of the research is satisfactory for fitting. 
Table 1. Fitting indexes of the structural model

\begin{tabular}{ccc}
\hline Fitting Index & Desirable Value & Result \\
\hline$\chi^{2} / d f$ & $<8.00$ & 4.657 \\
GFI & $>0.90$ & 0.913 \\
RMR & $<0.05$ & 0.021 \\
NFI & $>0.90$ & 0.978 \\
IFI & $>0.90$ & 0.905 \\
CFI & $>0.90$ & 0.926 \\
\hline
\end{tabular}

\section{Interpretation of Fitting Indexes}

\section{Chi-Square}

Chi-Square is regarded as the most conventional and applicable fitting index in the Structural Equations Modelling (SEM) which states the importance of the difference between fitted model and covariance matrix of an observed sample. (Bentler \& Bonett, 1980; Marsh et al., 1998; Dion, 2008) The smaller the value of Chi-Square index, the better the fitting of data to the model (Byrne et al., 1989). A useful criterion for determining the applicability of Chi-Square index is that the value of Chi-squared divided by the degree of freedom must be less than 8 , and as it equals 4.657 in the current research, so the model has a good fitness.

\section{GFI}

This index is premised on the average of the correlation coefficients between variables in the model. GFI index varies from 0 to 1 and values higher than 0.9 indicate a good model. The value of GFI index in the current research equals 0.913 implying the satisfactory fitting of the model.

\section{RMR}

This index is calculated based on the residual matrix and values less than 0.05 indicate suitable fitting of the model. In this research RMR is equal to 0.021 .

\section{IFI, CFI, NFI}

Provided that these indexes have a value higher than 0.9 , the validity of the model's fitting is substantiated (Houman, 2005, pp. 235-244). In addition, few researchers consider the cut point of 0.8 as the goodness-of-fit for the NFI index (Ghasemi, 2009, p. 104). Concerning the fact that the values of aforementioned indexes are higher than 0.9 in this research, it is concluded that the fitting of the given model fits the collated data.

\subsection{Hypotheses Test}

Based on the test results, if significance level is less than 0.05 , it can be construed that there exists a significant relationship between organizational health and other variables.

Table 2. Pearson correlation test

\begin{tabular}{|c|c|c|}
\hline & & Organizational Health \\
\hline \multirow{3}{*}{ Ethics } & Pearson Correlation & $.540^{* *}$ \\
\hline & Significance Level & .000 \\
\hline & Number & 230 \\
\hline \multirow{3}{*}{ Communication } & Pearson Correlation & $.884^{* *}$ \\
\hline & Significance Level & .000 \\
\hline & Number & 230 \\
\hline \multirow{3}{*}{ Trust } & Pearson Correlation & $.449^{* *}$ \\
\hline & Significance Level & .000 \\
\hline & Number & 230 \\
\hline \multirow{2}{*}{ Motivation } & Pearson Correlation & $.833^{* *}$ \\
\hline & Significance Level & .000 \\
\hline
\end{tabular}




\begin{tabular}{|c|c|c|}
\hline & Number & 230 \\
\hline \multirow{4}{*}{ Responsiveness } & Pearson Correlation & $.428^{* *}$ \\
\hline & Significance Level & .000 \\
\hline & Number & 230 \\
\hline & Pearson Correlation & $.617^{* *}$ \\
\hline \multirow[t]{2}{*}{ Commitment } & Significance Level & .000 \\
\hline & Number & 230 \\
\hline \multirow{3}{*}{ Leadership } & Pearson Correlation & $.793^{* *}$ \\
\hline & Significance Level & .000 \\
\hline & Number & 230 \\
\hline \multirow{3}{*}{ Reputation } & Pearson Correlation & $.848^{* *}$ \\
\hline & Significance Level & .000 \\
\hline & Number & 230 \\
\hline \multirow{3}{*}{ Identify performance } & Pearson Correlation & $.849^{* *}$ \\
\hline & Significance Level & .000 \\
\hline & Number & 230 \\
\hline \multirow{3}{*}{ Culture } & Pearson Correlation & $.636^{* *}$ \\
\hline & Significance Level & .000 \\
\hline & Number & 230 \\
\hline \multirow{3}{*}{ Capability } & Pearson Correlation & $.369^{* *}$ \\
\hline & Significance Level & .000 \\
\hline & Number & 230 \\
\hline \multirow{3}{*}{ Efficiency } & Pearson Correlation & $.559^{* *}$ \\
\hline & Significance Level & .000 \\
\hline & Number & 230 \\
\hline \multirow{3}{*}{ Resource-usage } & Pearson Correlation & $.744^{* *}$ \\
\hline & Significance Level & .000 \\
\hline & Number & 230 \\
\hline \multirow{3}{*}{ Tendency } & Pearson Correlation & $.404^{* *}$ \\
\hline & Significance Level & .000 \\
\hline & Number & 230 \\
\hline \multirow{3}{*}{ Path-Objective } & Pearson Correlation & $.613^{* *}$ \\
\hline & Significance Level & .000 \\
\hline & Number & 230 \\
\hline \multirow{3}{*}{ Collaboration } & Pearson Correlation & $.513^{* *}$ \\
\hline & Significance Level & .000 \\
\hline & Number & 230 \\
\hline \multirow{3}{*}{ Innovation } & Pearson Correlation & $.534^{* *}$ \\
\hline & Significance Level & .000 \\
\hline & Number & 230 \\
\hline \multirow{3}{*}{ Coordination } & Pearson Correlation & $.731^{* *}$ \\
\hline & Significance Level & .000 \\
\hline & Number & 230 \\
\hline
\end{tabular}

There are significant relationships between the 18 variables in the model and organizational health in the Gas Transmission Office in Area 7 (owing to the significance levels less than 0.05). Resultantly, the research's hypotheses are validated. 


\subsection{The Ranking of Variables}

In this stage all of the desirable variables are compared by virtue of Paired Comparison Analysis. These comparisons determine the weight of each factor compared to its paired alternative. Ultimately, the delicate logic behind AHP integrates the resultant matrices of paired comparisons so that an optimized decision is acquired (Azar, 1991). Table 5 clearly shows the weight of all variables.

Table 3. Ranking of variables

\begin{tabular}{ccc}
\hline Priority & Coefficient of significance & Variable \\
\hline 1 & 0.118 & Communication \\
2 & 0.112 & Leadership \\
3 & 0.094 & Motivation \\
4 & 0.071 & Resource usage \\
5 & 0.070 & Reputation \\
6 & 0.070 & Coordination \\
7 & 0.067 & Identify \\
8 & 0.067 & Culture \\
9 & 0.054 & Path-objective \\
10 & 0.041 & Commitment \\
11 & 0.040 & Efficiency \\
12 & 0.035 & Innovation \\
13 & 0.031 & Ethics \\
14 & 0.031 & Collaboration \\
15 & 0.030 & Responsiveness \\
16 & 0.030 & Trust \\
17 & 0.020 & Tendency \\
18 & 0.017 & Capability \\
\hline
\end{tabular}

\section{Discussion}

Organizational health is amongst the paramount parameters affecting the quality and efficiency of organizations. Organizations need to be healthy in order to acquire a sustainable superiority; in fact organizational health creates the apt environment for eminence and predominance. Specifically due to the profound role of energy in public's welfare, a great number of human resources and their principal role in public services, the organizational health in the Gas Transmission Office in Area 7 is regarded as a crucial issue. In the current research the influential factors in organizational health were investigated. The research's findings suggest that there are significant relationships between collaboration, reputation, employees' efficiency, identify performance, resource planning, ethics and the organizational health; the results are consistent with the findings of Lynden and Klingle (2000). The communication factor bears a significant relationship with organizational health which is in line with the studies conducted by Ahanchian and Monidari (2004) and Keller and Price (2011). The organizational commitment has a significant relationship with the organizational health which is similar to the findings of Heinonen and Saarimaa (2009), Pateel (2002), Mishara et al. (2009) Saurabh and Mmishara (2008), Mayler and skorman (2008), Rajabi farjad et al. (2014), Ferdosi et al. (2012), Salarzehi et al. (2013), Mishara et al. (2009) and Ghorbanian (2011). The leadership and organizational health are significantly related and it is verified by Miandari et al. (2014), Keller and Price (2011) studies. There are significant relationship between path-objective, outward tendency, motivation, and integrity and the organizational health and similarly this finding is in line with keller and Price (2011). The trust factor and organizational health are codependent and this result is agreed by Zolghadrnasab's results (2005). There is also a significant relationship between organization's culture and organizational health which is confirmed by the findings of Miandari et al. (1993), Rabeie and bigdeli (2011), keller and Price (2011). The responsiveness factor is related to organizational health and it is in accordance with 
studies of Miandari et al. (2014), Rabeie and bigdeli (2011) and keller and Price (2011). The employees' capabilities and organizational health are significantly related and it is agreeable with Miandari (2014) and Keller, Price (2011) studies. The innovation has a significant relationship with the organizational health which is in accordance with the findings of Kimpeston, sonaband (1973) and Keller, Price (2011). In order to examine the principal assumption that influential factors in organizational health have unequal weights, the Expert Choice software was utilized and the results indicated that communication factor was ranked 1st with a weight equal to 0.118 and the capability variable is ranked as the last one having a weight of 0.017. Exploiting the Structural Equations Modelling, validity of the research's model was scrutinized and the results imply that the relationships between the variables of the initial model is of significant importance; hence, all of the studied variables could be validated as influential factors in organization health in the Gas Transmission Office in Area 7. Resultantly, the final model was validated.

\section{Conclusion}

The results of the study show that a healthy organization is a moral oriented one where political behaviours are avoided; interaction with environment is dynamic, employees are highly committed and motivated, and there is sympathy and participation in doing affairs. One of outstanding signs of a healthy organization is its clear objectives and commission, because the clarity of the organization is the foundation of organizational health. Therefore its employees know the organization's values and based on them they determine the scope of their behavior. The leaders of a healthy organization, via appropriate and continuous planning, attempt to discover the employee's potential abilities and talents and actualize them. They also recognize the employee's performance and evaluate it based on the organization's values, not based on their own taste. A healthy organization always seeks the continuous improvement of the activities, creativity increases, and innovation.

Consequently, as human's health causes him to be lively and most importantly to survive, in an organization, too, it elevates the spirit of constructing, the achievement of organizational objectives, and finally the long term survival of the organization. As a final remark, based on the proposed mode which shows the factors affecting organizational health, the following are suggested:

Applying media training to increase the employee's' capability.

Improving accountability and responsibility taking through connecting the individual's performance to the reward mechanism and the compensation for his or her services.

Creating a true understanding of responsibility, job objectives, and performance expectations.

Creating a true understanding of job performance and the tool for appreciating the employee.

Respecting free expression of ideas and behaving fairly and void of discrimination.

Strengthening group working in the organization and inhibiting individualism.

Establishing a suitable bed for innovating in the organization, i.e., holding brainstorming meetings to take advantage of employee's new ideas.

\section{Research Limitations}

The current research is one of a few studies that studied the organizational health in a specific organization as most of the researches are concentrated on organizational health in Schools and colleges. As a result, there was a scarcity of literature an resources regarding the organizational health.

\section{Suggestions for Future Studies}

1. Extensive and deliberate studies can be exercised on organizational health concept and its significance so that a unique definition and measurement criteria can be specified.

2. It is highly recommended that prospective researchers identify the influential factors in organizational health with valid instruments other than questionnaires.

3. It is suggested that prospective researchers carry out detailed studies on each of the influential factors; say, one can focus on diverse attitudes towards effective leadership to study the leadership variable.

4. It is recommended that the concept of organizational reform be incorporated in future studies with a view to achieving organizational health.

\section{Acknowledgments}

I should like to thanks Gas Transmission Office in Area 7 for its financial support. 


\section{References}

Ahanchian, M. R., \& Monidari, R. (2004). The relationship between Managers' Communicative Skills and Organization Health. Research Journal of Humanity and Social Science, 4(12), 41-60.

Akbari, M., Shakiba, H., Zyaei, M. S., Marzban, S. H., \& Razi, S. (2013). A Study of Realationship between Organizational Health and Corporate Entrepreneurship (Case Study: Tehran University). Public Administration, 5(1), 1-20.

Anderson, J., \& Gerbing, D. W. (1984). The effect of sampling error on convergence, improper solutions, and goodness of fit indices for maximum likelihood confirmatory factor analysis. Psychornetrika, 49, 155-173. http://dx.doi.org/10.1007/BF02294170

Ansari, M. A., Ostadi, H., \& Javari, F. (2009). A Study of of Realationship between Organizational Health and Positive Attitudes of Employees at Tax Office of Isfahan City. Journal of Taxes, new era, 6, 41-65.

Argyris, Ch. (1958). The Organization: What Makes It Healthy?. Harvard Business Review, 36(6), 107-116.

Azar, A. (1994). AHP New Technique for Group Decision Making. Knowledge Management, 27 \& 28.

Bentler, P. M., \& Bonett, D. G. (1980). Significance Test and Goodness of fit in the Analysis of covariance Structures. Psychological Buletin, 88, 588-606.

Bruhn, J. G. (2001). Trust and the Health of Organisations. New York: Kluwer Academic/Plenum Publishers.

Byrne, B., Shavelson, R., \& Muthén, B. (1989). Testing for the equivalence of factor covariance and mean structures: the issue of partial measurement invariance. Psychol Bull, 105, 456-466. http://dx.doi.org/10.1037/0033-2909.3.456

Cotton, P., \& Hart, M. P. (2003). Occupational Wellbeing and Performance: A Review of Organizational Health Research. AustralianPsychologist, 38(2), 118-127. http://dx.doi.org/10.1080/00050060310001707117

De Smet, A., Loch, M., \& Schaninger, W. (2006). Performance and health: Insearch of sustainable excellence. New York: McKinsey \& Company. London: Kogan Page.

Dion, P. A. (2008). Interpreting Structural Equation Modeling Results: A Reply to Martin and Cullen. Journal of Business Ethics, 83, 365-368. http://dx.doi.org/10.1007/s10551-007-9634-7

Dive, B. (2004). The Healthy organization a Revolutionary Approach to people \& Management (2nd ed.). London: Kogan Page.

Dive. B. (2008). The accountable leader, Developing effective leadership through managerial. London: Kogan Page.

Farahbakhsh, S. (2009). Managing of Human Reslations. Tehran: Ayyij.

Ferdosi, M. H., Marashian, F., \& Talebpour, M. (2012). The relationship between personality characteristics and organizational commitment and organizational health in staff Tax office of Sport and Youth sports management of Khuzestan province. Sports Management Studies, 15, 173-188.

Ghasemi, V. (2009). Introduction to Structural Equation Modeling. Tehran: Jame Shenasan.

Ghorbanian, P. (2011). The relationship between organizational health and organizational commitment of public school teachers in Hamadan 2010-2011 (Master's thesis). Bu Ali Sina University, Hamedan, Science Faculty, Iran.

Ghorbanshiroudi, M. (2011). The Relationship between Organizational Health and Style of managers Management (Master's thesis). Islamic Azad University of Sanandaj, Iran.

Haunschild, A. (2003). Humanization through discipline? Foucault and the goodness of employee health programmes. Tamara: Journal of Critical Postmodern Organisation Science, 2(3), 46-59.

Heinonen, S., \& Saarimaa, R. (2009). Better job satisfaction through quality of work life- how can telework help? Hong Lu, E., Alison, K. W.

Houman, H. A. (2005). Structural equation modeling using LISREL software. Tehran: samt.

Hoy, W. K., \& Feldman, J. A. (1987). Organizational health: the concept and its measure. Journal of Research and Development in Education, 20(4), 30-37.

Hoy, W. K., \& Miskel, C. G. (1991). Educational administration: Theory, research and practice (4th ed.). New York: McGraw-Hill. 
Hoy, W. K., \& Miskel, C. G. (2003). Educational Administration: Theory, Research and Practice (Saeid Abbaszadeh). Miskel, M. Urmia. Urmia University. (Persian).

Hoy, W. K., Tarter, C. J., \& Kottkamp, R. B. (1991). Open schools/Healthy schools. Newbury Park, CA: Sage.

Jahed, H. A. (2005). Organizational Health. Tadbir, 159, 16-21.

Kalantari, K. H. (2009). Structural equation modeling in social studies, economics (with LISREL program and Sympls) (1st ed.). Tehran: Saba culture.

Keller, S., \& Colin, P. (2011). Beyond Performance: How Great Organizations Build Ultimate Competitive Advantage (Kindle Edition).

Kimpston, R. D., \& Sonnabend, L. C. (1975). Public school: the interrelationship between Organizational health and innovativeness and between Organizational health and staff characteristic. Journal of research and Development in education, 4, 30 .

Klingle, W., \& Lynden, J. A. (2000). Supervising Organizational Health. Supervision Journal.

Korkmaz, M. (2007). The effect of Leadership style onorganizational Health. Educational Research Quarterly, 3, $22-54$.

Larson, J. S. (1999). The conceptualization of health. Medical Care Research and Review, 56, 123-136. http://dx.doi.org/10.1177/107755879905600201

Latifi, F., \& Kyani, G. H. (1999). Organizational health indicators in the 21 st century. Tadbir, 100, 22-28.

Lencioni, P. (2000). The Four Obsessions of an Extraordinary Executive. Jossey-Bass.

Lencioni, P. (2012). The advantage: Why organizational health trums everything else in business. San Francisco: Jossey-Bass.

Marsh, H. W., Bella, J., \& RyMacdonald, R. P. (1998). Goodness of fit indices in confirmatory factor analysis Effect of sample size. Phychological Bulletin, 103, 391-411. http://dx.doi.org/10.1037/0033-2909.103.3.391

Mayler, W., \& skorman, P. (2008). Assessment of influential factors on employees organizational commitment in different departments . Journal of Safety Research, 25, 42-45.

Miandari, K., Abedi jafari, H., Najari, R., \& Mhdipour, R. (2014). Offer a hybrid model to explain the design and healthy organization "The Case of the Ministry of Cooperatives, Labour and Social Welfare". Journal of Organizational Behavior, 3(1 and 2), 47-74.

Miles, M. B. (1969). Planned change and organizational health: Figure and ground. In F. D. Carver, \& T. J. Sergiovanni (Eds), Organizations and human.

Miller, R. L., Griffen, M. A., \& Hart, P. (1999). Personality and organizational health: The role of conscientiousness. Work \& Stress: An International Journal of Work, Health \& Organizations, 13(1), 7-19.

Mishara, gayatra, parvash, Kumar, patanyac. (2009). The multi menials natural of organizational commitment in a non western context. Journal of Management Development, 1, 71-82.

Omoyemiju, M. A., \& Adediwura, A. A. (2011). A StudyofTeacher 's Perception of Schools Organizational Health OsunStarte. World Journal of Education, 1(1), 165-170.

Parsons, T., Bales, R. F., \& Sils, E. A. (1953). Working papers in the theory of action. Glencoe, IL: Free Press.

Pateel, C. (2002). Examination of Organizational health and organizational commitment among industrial employees. Journal Health Train, 4, 180-195.

Polanyi, M. (2004). Healthy Organization Practices: A Synthesis of Emerging Work-Health Research. Saskatchewan Poupulation Health Evaluation and Research Unit, University of Regina, Background Paper for, Creating Healthy and Productive Workplace Practices, A Multi Stakeholder Conference, May 11-13.

Rabeei, A., \& Bigdeli, M. (2011). Cultural pathology in health promotion office at government and non-governmental agencies. Journal of Religion and communications, 18(1), 187-206.

Rajabifarjad, H., Malmir, A., \& Taheri, A. (2014). The relationship between organizational health and organizational justice and organizational commitment among employees of Hamadan tax office. Journal of Human Resource Management and Support, 9(31), 23-44.

Saatchi, M. (1991). Patient manager, Healthy employees, Healthy manager, Patient Employees. Tadbir, 2(19).

Saedi, S., Kalatnari, G., \& Mori, N. (2010). The Relationship between quality of work and organizational health 
and job satisfaction. Journal of industrial/organizational psychology, 1(4), 55-64.

Salarzehi, H., Oraei Yazdani, B., \& Pourhasan, R. (2013). A Study of Effect of Factors on organizational health promotion (Case Study: Three municipal areas of Zahedan). Knowledge assessment, 5(15), 85-108.

Saurabh, Kr. T., \& Mmishara, P. C. (2008). Work steers and health as- predicators of organizational of organizational commitment. Journal of the Indian academy of applied psychology, 2, 267-277.

Schreibera, J. B. (2002) . Reporting Structural Equation Modeling and ConfirmatoryFactor Analysis Results: A Review. The Journal of Educational Research, 99(6), 323-337. http://dx.doi.org/10.3200/JOER.99.6.323-338

Sheykhi, M. H. (2011). Factors affecting the health and growth of the administrative system of moral values. Islam and Management Research, 1(2), 126-199.

Terickt, L. E. (2002). Individual and Organizational Health. Historical and Current Perspectives on Stress and Health, 2, 117-141.

Tsui, K, T., \& Cheng, Y. C. (1999). School organizational health and teacher commitment: A contingency study with multi-level analyses. Educational Research and Education, 3, 429-468.

Williams, S. (1994). Ways of creating healthy work organizations. In C. L. Cooper, S. Cooper, \& S. Williams (Eds.), Creating Healthy Work Organizations. Chichester, West Sussex: John Wiley \& Sons.

Zolghadrnasab, M. (2005). The Relationship between Organizational Health and organizational commitment of teachers in primary schools in the academic year 2003-2004 in Hamedan (Master's thesis). University of Teacher Education, Faculty of Psychology, Tehran, Iran.

\section{Copyrights}

Copyright for this article is retained by the author(s), with first publication rights granted to the journal.

This is an open-access article distributed under the terms and conditions of the Creative Commons Attribution license (http://creativecommons.org/licenses/by/3.0/). 